Please do not remove this page

RMIT

UNIVERSITY

\title{
Clear model fluids to emulate the rheological properties of thickened digested sludge
}

Eshtiaghi, Nicky; Yap, Shao; Markis, Flora; Baudez, Jean; Slatter, Paul

https://researchrepository.rmit.edu.au/esploro/outputs/9921858353801341/filesAndLinks?institution=61RMIT_INST\&index=null

Eshtiaghi, N., Yap, S., Markis, F., Baudez, J., \& Slatter, P. (2012). Clear model fluids to emulate the rheological properties of thickened digested sludge. Water Research, 46(9), 3014-3022.

https://doi.org/10.1016/j.watres.2012.03.003

Document Version: Accepted Manuscript

Published Version: https://doi.org/10.1016/j.watres.2012.03.003

Repository homepage: https://researchrepository.rmit.edu.au

(c) 2012 Elsevier Ltd. All rights reserved.

Downloaded On 2023/04/26 21:44:28 +1000

Please do not remove this page 
Thank you for downloading this document from the RMIT Research Repository.

The RMIT Research Repository is an open access database showcasing the research outputs of RMIT University researchers.

RMIT Research Repository: http://researchbank.rmit.edu.au/

\section{Citation:}

Eshtiaghi, N, Yap, S, Markis, F, Baudez, J and Slatter, P 2012, 'Clear model fluids to emulate the rheological properties of thickened digested sludge', Water Research, vol. 46, no. 9 , pp. 3014-3022.

See this record in the RMIT Research Repository at:

http://researchbank.rmit.edu.au/view/rmit:15574

Version: Accepted Manuscript

Copyright Statement: (c) 2012 Elsevier Ltd. All rights reserved.

Link to Published Version:

http://dx.doi.org/10.1016/j.watres.2012.03.003 


\section{Accepted Manuscript}

Clear model fluids to emulate the rheological properties of thickened digested sludge

Nicky Eshtiaghi, Shao Dong Yap, Flora Markis, Jean-Christophe Baudez, Paul Slatter

PII: $\quad$ S0043-1354(12)00166-2

DOI: $\quad$ 10.1016/j.watres.2012.03.003

Reference: WR 9153

To appear in: Water Research

Received Date: 1 November 2011

Revised Date: 29 February 2012

Accepted Date: 2 March 2012

Please cite this article as: Eshtiaghi, N., Yap, S.D., Markis, F., Baudez, J.-C., Slatter, P., Clear model fluids to emulate the rheological properties of thickened digested sludge, Water Research (2012), doi: 10.1016/j.watres.2012.03.003

This is a PDF file of an unedited manuscript that has been accepted for publication. As a service to our customers we are providing this early version of the manuscript. The manuscript will undergo copyediting, typesetting, and review of the resulting proof before it is published in its final form. Please note that during the production process errors may be discovered which could affect the content, and all legal disclaimers that apply to the journal pertain. 
Graphical abstract:

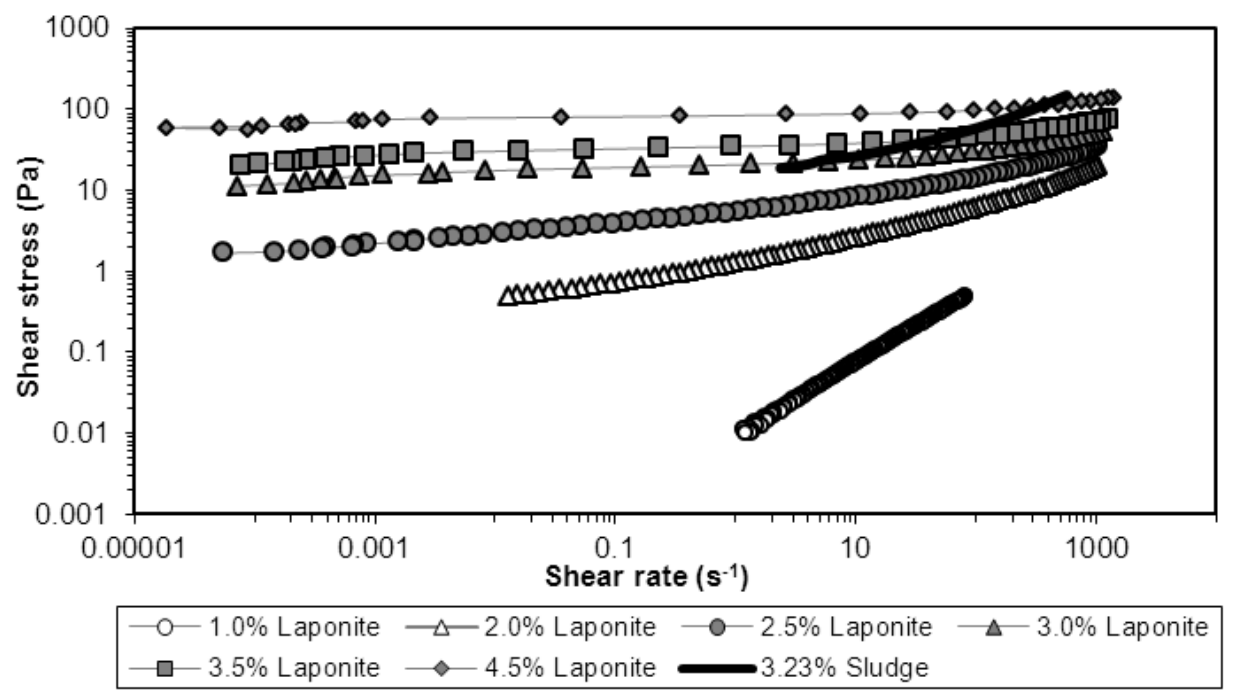

Anaerobic digestion is a key treatment process for solids treatment and pathogen reduction. Due to the inherent opacity of sludge, it is impossible to visualize the mixing and flow patterns inside an anaerobic digester. Therefore, choosing an appropriate transparent model fluid which can mimic the rheological behaviour of sludge is imperative for visualization of the hydrodynamic functioning of an anaerobic digester. 


\title{
CLEAR MODEL FLUIDS TO EMULATE THE RHEOLOGICAL
} PROPERTIES OF THICKENED DIGESTED SLUDGE

\author{
Nicky Eshtiaghi', Shao Dong Yap ${ }^{1}$, \\ Flora Markis $^{1^{*}}$, Jean-Christophe Baudez ${ }^{1,2}$, Paul Slatter ${ }^{1}$ \\ 1-Rheology and Materials Processing Centre, Dept. of Chemical Engineering, RMIT University, Victoria, Australia, 3001 \\ 2- Irstea, UR TSCF, Domaine des Palaquins, F-03150 Montoldre, France \\ nicky.eshtiaghi@rmit.edu.au, Tel:+61-3-9925-9554 \\ flora.markis@student.rmit.edu.au \\ paul.slatter@rmit.edu.au
}

\section{ABSTRACT}

Optimizing flow processes in wastewater treatment plants requires that designers and operators take into account the flow properties of the sludge. Moreover, due to increasingly more stringent conditions on final disposal avenues such as landfill, composting, incineration etc., practitioners need to produce safer sludge in smaller quantities. Anaerobic digestion is a key treatment process for solids treatment and pathogen reduction. Due to the inherent opacity of sludge, it is impossible to visualize the mixing and flow patterns inside an anaerobic digester. Therefore, choosing an appropriate transparent model fluid which can mimic the rheological behaviour of sludge is imperative for visualization of the hydrodynamic functioning of an anaerobic digester.

Digested sludge is a complex material with time dependent non-Newtonian thixotropic characteristics. In steady state, it can be modelled by a basic power-law. However, for 
23 short-time processes the Herschel-Bulkley model can be used to model liquid-like

24 properties.

25 The objective of this study was to identify transparent model fluids which will mimic the

26 behaviour of real sludge. A comparison of three model fluids, Carboxymethyl Cellose

27 (CMC), Carbopol gel and Laponite clay revealed that these fluids could each model certain

28 aspects of sludge behaviour. It is concluded that the rheological behaviour of sludge can be

29 modelled using CMC in steady state flow at high shear rates, Carbopol gel for short-time

30 flow processes and Laponite clay suspension where time dependence is dominant.

32 Keywords: Thickened municipal digested sludge, rheology, thixotropic properties, Short time

33 process, Steady state operation, model fluids,

\section{1. Introduction}

36 Optimal and efficient design and operation of waste water treatment plants requires

37 accurate prediction of the hydrodynamic functioning of the associated plant such as pumps,

38 heat exchangers and anaerobic digester mixing. Accurate flow behaviour prediction of

39 these engineering hydrodynamic processes requires the rheological characteristics of the

40 sludge as input (Slatter, 2011).

41 Since the beginning of the seventies with the pioneering work of Colin (1970), and

42 Bhattacharya (1981), rheological measurements have proved to be of great interest to

43 quantitatively estimate the physical consistency of sewage sludge. Sewage sludge is often 
44 seen as a complex mixture. The literature presents a wide variety of results: sludge is

45 always non-Newtonian (Campbell and Crescuollo, 1982), exhibits a yield stress (Baudez

46 and Coussot, 2001; Mori et al., 2006) or not (Valioulis, 1980), is shear-thinning (Chaari et

47 al., 2003) or thixotropic (Tixier et al., 2003). Most of the rheological models used to

48 describe sludge behaviour are a simple power-law (Moeller and Torres, 1997), the Bingham

49 model (Sozanski et al., 1997; Guibaud et al., 2003) or the Herschel-Bulkley model (Slatter,

50 1997; Baudez, 2001). The Sisko model, Cross viscosity model, truncated power law model

51 (Baudez, 2008) have been also used. Slatter (2008) has shown that the sludge rheology

52 plays a fundamentally important role in analysing the hydrodynamic behaviour of the

53 sludge, as it flows through the tertiary treatment process.

54

55

$$
\tau=K \dot{\gamma}^{n}
$$

Eq.1

56

$$
\tau=\mu_{B} \dot{\gamma}+\tau_{y}
$$

Eq.2

57

$$
\tau=K \dot{\gamma}^{n}+\tau_{y}
$$

Eq.3

58

$$
\tau=\mu_{\infty} \dot{\gamma}+K \dot{\gamma}^{n}
$$

Eq.4

59

$$
\frac{\mu-\mu_{\infty}}{\mu_{0}-\mu_{\infty}}=\frac{1}{1+K \dot{\gamma}^{m}}
$$

Eq. 5

60

$$
\frac{\tau}{\tau_{C}}=\left(\frac{\dot{\gamma}}{\dot{\gamma}_{C}}\right)^{n}
$$

Eq.6

62 A power-law fluid (Eq.1) is a type of generalized non-Newtonian fluid, where $\tau$ is the

63 shear stress, $\dot{\gamma}$ is the shear rate, ' $\mathrm{K}$ ' is the fluid consistency index, 'n' is the flow

64 behaviour index. The pseudoplastic model can be used to model the shear thinning zone of 
65 the rheogram of sludge suspensions (an intermediate shear rate range). In Bingham plastic 66 model (Eq.2), sludge is rigid when shear stress ( $\tau$ ), has a value less than a critical value $\tau_{y}$.

67 Once the critical shear stress (or "yield stress") is exceeded, the material flows. The

68 Herschel-Bulkley model (Eq.3) compared to the power-law model, the additional term

69 yield stress $\left(\tau_{y}\right)$ quantifies the amount of stress that the fluid may experience before it

70 yields and begins to flow. The physical reason for this behaviour is that sludge may contain

71 particles or large molecules with have some kind of interaction, creating a weak solid

72 structure and a certain amount of stress is required to break this structure and produce flow.

73 Once the structure has been broken, the particles move with the liquid under viscous forces.

74 If the stress is removed, the particles associate again (Chhabra and Richardson, 2008). This

75 process also exists under shear at low shear stress (Tabuteau et al., 2006; Baudez, 2008).

76 The advantage associated with employing the Herschel-Bulkley fluid model (Eq.3)

77 describes both pseudoplastic (rheogram curvature) as well as the Bingham model (yield

78 stress) (Slatter, 1999); however, the model does not take into account the Newtonian

79 asymptotes at low and high shear rates (Slatter, 1999). At high shear rate, the model

80 suggested by Baudez et al. (2011a), can be seen as a start to improve rheological

81 characteristisation of sludge. Both Bingham plastic and Herschel-Bulkley models can

82 characterize the sludge behaviour from rest to flow. It is also important to note that in some

83 cases, sludge may present slight thixotropic behaviour (Tabuteau et al., 2006, Terashima et

84 al, 2009), which causes hysteresis on flow curves although (Baudez, 2006) demonstrated

85 that hysteresis loop inside the rheogram cannot be used to define the thixotropic character 
86 of a sludge. This is most frequently explained by the time-dependent disintegration of

87 internal structure of a liquid suspension as a result of the application of shear stress.

88 The Sisko model (Eq.4) can be used to characterize the flow behaviour of sludge in the

89 intermediate and high shear rates range, where the apparent viscosity tends to a limiting

90 value (plateau) (Mori et al. , 2006). The Cross viscosity fluid model (Eq.5) is a four

91 parameter model that relates the fitting parameters $K$ (parameter with dimension of time)

92 and $m$ (dimensionless material parameter) to the zero shear viscosity, $\mu_{0}$ and infinite shear

93 viscosity, $\mu_{\infty}$ (Sybilski, 2011). Eq.5 is further simplified and presented in Eq. 6 because

94 high shear rates cannot be accurately measured and thus the value of $\mu_{\infty}$ cannot be

95 determined; it can also be assumed that $\mu>\mu_{\infty}$ (Sybilski, 2011).

96

$$
\mu=\frac{\mu_{0}}{1+K \dot{\gamma}^{m}}
$$

Eq.6

Baudez (2008) defined a critical shear stress, $\dot{\tau}_{C}$ (with corresponding critical shear rate, $\dot{\gamma}_{C}$ )

99 which below that the solid structure rebuilds even under shear. In fact, below the critical

100 shear stress, colloidal forces tend to rebuild the solid structure (physical aging) and shearing

101 forces tend to break the solid structure (shear rejuvenation). As soon as the critical shear is

102 reached, the solid structure is completely collapsed, and fluid starts flowing which the

103 relationship between the shear rate and the shear stress can be defined with a truncated

104 power-law (Eq.6) model. He also correlates the higher degree of thixotropy of the material

105 to stronger interactions between the solid particles. 
107 Sludge rheology is complex and always evolves with time due to ageing and microbial

108 activity. The time-dependent characteristics of sludge rheology make the measurement of

109 physical parameters difficult and the results obtained are often unreliable because of this.

110 Therefore it cannot be used as a reference material for industrial process design or

111 controlled experiments. As a result of this, researchers have been trying to find a suitable

112 transparent model fluid that mimics the behaviour of sludge. Most studies have focussed on

113 the characterisation and modelling of activated sludge, but there are very few studies on

114 digested sludge. For activated sludge, the proxy materials that have been studied so far

115 include kaolin suspension for the yield stress determination (Spinosa and Lotito, 2003)

116 polymeric gels (Legrand et al., 1998), polyvinyl chloride (PVC) suspensions (Bongiovanni,

117 1998) and polystyrene latex (Sanin and Vesilind, 1996; Örmeci and Vesilind, 2000).

119 To model the flow properties of activated sludge in liquid regime, kaolin suspensions are 120 often used (Héritier et al., 2010) due to its similarity in rheological behaviour and can be

121 described by a Herschel-Bulkley model (Baudez, 2001; Masalova et al., 2006). Sanin and

122 Vesilind (1996) reported a synthetic sludge made up of polystyrene latex particles and

123 polysaccharide-alginate. Their experiments demonstrated that it is possible to create

124 chemical surrogate sludge by using bacteria like particles, extracellular resemble

125 polysaccharides, and cations common to activated sludge at typical quantities. However,

126 their synthetic sludge shows poor flocculation behaviour due to the absence of filamentous

127 microorganism which is the backbone for overall floc structure in activated sludge (Nguyen

128 et al., 2007a). Örmeci and Vesilind (2000) improved the characteristic of synthetic sludge

129 by adding cellulose fibres to simulate the filamentous microorganisms in activated sludge, 
130 which results in stronger floc formation and better dewaterability as well as settling, though

131 the fibres are hard to dissolve in water (Baudez et al., 2007). They observed that both

132 calcium ions and alginate are important to promote the floc formation in synthetic sludge,

133 which is later confirmed by Nguyen et al. (2007a; 2007b; 2008,). Dursun et al. (2004)

134 compare the physical characteristic of the synthetic sludge to activated sludge. They noted

135 that the synthetic sludge may be an adequate surrogate in terms of electrokinetic and

136 rheological properties but does not duplicate the properties and conditionability of activated

137 sludge. Therefore the application of this synthetic sludge is only valid for qualitative or

138 mechanics studies. Baudez et al. (2007) suggested that it is necessary to consider granular

139 arrangement by adding micro-aggregates (Jorand et al., 1995) into synthetic sludge as real

140 sludge does not contain individual bacterial cells only.

142 Baudez et al. (2007) commented that standard methodologies should be developed to 143 prepare synthetic suspensions that mimic behaviour of both inorganic and organic sludge

144 for lab testing. They showed that a mixture of kaolin and calcite/quartz sand in water with 145 relative ratio ranges from $90 / 10 \%$ to $75 / 25 \%$ was able to well describe the behaviour of real

146 inorganic sludge. As for organic sludge, it is developed based on the recipe by Müller and

147 Dentel (2002) and Dursun et al. (2004) and consists of alginate, cellulose, yeast, bovine,

148 serum albumin, stearic acid, and calcium as well as potassium ions in water. However,

149 preparation of such recipe could be difficult as it requires one to have extensive knowledge

150 on surface chemistry and colloidal system to ensure the synthetic sludge behaves exactly

151 the same as the real sludge. Also, rheological measurement needs to be performed on the 152 synthetic sludge to examine its behaviour to compare with activated sludge. 
154 It is known that anaerobic digestion is a key treatment process for solids treatment, and

155 odour and pathogen reduction. Due to the inherent opacity of sludge, it is impossible to

156 visualize the mixing and flow patterns inside an anaerobic digester. Therefore, choosing an

157 appropriate transparent model fluid that can mimic the rheological behaviour of sludge is

158 imperative for visualization of the hydrodynamic functioning of an anaerobic digester. The

159 idea of model fluid for sludge is to find a material that is less complicated but at the same

160 time still be able to simulate the sludge behaviour. There is no study to find the

161 representative, safe and non-smelly fluid which could mimic the rheological behaviour of

162 sludge. Rheological properties of Carbopol, CMC and Laponite have been investigated in

163 the past decades for various applications in food science and surface coating but very few

164 compared their properties to the behaviour of sludge. Baudez et al. (2011b) recently have

165 examined that the similarity between soft glassy material and sludge, based on its dynamic

166 visco-elastic behaviour, i.e. the storage modulus $\left(G^{\prime}\right)$ and loss modulus $\left(G^{\prime \prime}\right)$, in the

167 temperature range of 10 to $60^{\circ} \mathrm{C}$ using strain and stress sweep tests. This work provides the

168 basis for future work in sludge characterisation utilizing the known characteristic of soft

169 glassy materials. Bonn $(1999 ; 2002)$ has shown that Laponite is soft glassy material. This

170 might be because Laponite is also a complex fluid like sludge, which complicates the

171 rheological analysis. The experimental results obtained here do indicate some similarities

172 between the rheological behaviour of Laponite and sludge under the influence of solid

173 suspension. But due to thixotropic behaviour of Laponite, in order to study the yield stress

174 effect of sludge, for example, on mixing system, a simple system is required. Coussot et al. 
175 (2009) also highlighted that the Carbopol gel is a type of material which can be an excellent

176 model of yield stress fluid. Therefore, Carbopol has been chosen to study for yield stress

177 effect of sludge. CMC sample also is a good example of fluid with no yield stress which

178 can be used to study the sludge property once a critical stress was applied and the yield

179 stress of sludge overcome. This paper aims to identify model fluids which will mimic the

180 behaviour of real sludge. These materials are widely available, non toxic and less

181 complicated to handle when use for sample preparations. Besides that, the rheological

182 properties of these materials have been well documented and therefore provide a strong

183 database to be adapted for sludge characterization. This enable a standard methods for

184 sludge characterization, as proposed by European Committee for Standardization (CEN)

185 (Spinosa, 2001), to be established so that technical language, methods and practice used

186 among researchers across the world for sludge characterization can be synchronized. For

187 this purpose the flow property and thixotropic behaviour of real sludge were measured then

188 by measuring similar property in model fluids, the model fluid could represent sludge

189 rheological behaviour in high shear, low shear. The best fit rheological model for

190 experimental data of model fluids and sludge is also presented.

191 2. MATERIAL AND METHODS

192 2.1 Material:

193 The digested sludge obtained from Mount Martha waste water treatment plant with total

194 solid suspended of $1.65 \%$ was concentrated to $3.23 \%$ TSS via vacuum filtration (Buchner

195 Funnel) for 6 hours. The model fluids which were used in this study were CMC, Carbopol, 196 and Laponite. Carboxymethylcellulose sodium salt (CMC) purchased from Sigma Aldrich 
$197\left(\mathrm{M}_{\mathrm{w}} 700\right.$ 000, D.S 0.9). Various aqueous CMC solutions were prepared by dissolving the

198 correct amount of CMC in deionised water at room temperature with continuous stirring

199 using an impeller mixer (Eurostar, power control Visc (Mixer)) at 1000 RPM. Carbopol

200 ®940 purchased from ACROS ORGANICS. Laponite RD purchased from Southern Clay

201 Products. Various concentrations of Carbopol were prepared by dissolving the correct

202 amount of Carbopol in deionised water at room temperature with continuous stirring using

203 an impeller mixer (Eurostar, power control Visc (Mixer)) at 1000 RPM. In order to

204 neutralize these Carbopol solutions, $1 \mathrm{M} \mathrm{NaOH}$ was added in a drop like manner whilst the

$205 \mathrm{pH}$ was simultaneously measured until a $\mathrm{pH}$ of 7 was reached. 1.7, 9.2, 19.0, $28.6 \mathrm{~mL}$

$206 \mathrm{NaOH}$ are required neutralizing $200 \mathrm{~g}$ of $0.1,0.5,1$, and $1.5 \%$ Carbopol, respectively. The

207 concentration of Laponite was prepared by dissolving the specific amount of Laponite

208 powder into the corresponding amount of tap water whilst continuous mixing it

209 simultaneously. After 48hr, the Laponite suspension made a gel structure.

\subsection{Method:}

211 The flow curve for thickened digested sludge at $25( \pm 1.0)^{\circ} \mathrm{C}$ was determined using the

212 Dynamic Stress Rheometer (SR200, Rheometrics) fitted with a couette geometry (inner

213 diameter: $29 \mathrm{~mm}$, outer diameter: $32 \mathrm{~mm}$, length: $44 \mathrm{~mm}$ ). A constant shear stress was first

214 imposed in order to pre-shear the sludge for 15 minutes and a relaxation time of 1 minute

215 was allowed. The flow curve was then obtained by imposing an increasing stress that

216 coincided with a shear rate less than $1000 \mathrm{~s}^{-1}$. This measurement was repeated for 3 different

217 samples coming from the same withdrawal at the WWTP in order to determine the

218 consistency of the results. The flow curve for model fluids at a constant temperature 
$219\left(25 \pm 1.0^{\circ} \mathrm{C}\right)$ were carried out by applying a shear stress within the range of 0.017 to $20 \mathrm{~Pa}$

220 for CMC and 30 to $300 \mathrm{~Pa}$ for Carbopol using the SR 200 rheometer. For higher shear rate,

221 shear rate controlled rheometer (Rheologica instruments AB, Scientex) with the couette

222 geometry (gap diameter $=3.0 \mathrm{~mm}$ ) for 50 to $500 \mathrm{RPM}$ range was used as the SR200 was

223 reached to its upper limit for torque measurement in the high shear rate range.

224 The thixotropic property of the concentrated digested sludge was measured at $25^{\circ} \mathrm{C}$ by

225 applying a pre-shear (corresponding to $200 \mathrm{~s}^{-1}$ ) for a duration of 15 minutes. Then without

226 relaxation time, a first shear stress corresponding to a shear rate of $100 \mathrm{~s}^{-1}$ was applied for

22715 minutes; a second shear stress corresponding to $5 \mathrm{~s}^{-1}$ was then applied and the first shear

228 stress was reapplied, each for duration of 15 minutes. The resulting shear rate versus time

229 graph was analyzed in order to describe the thixotropy of digested sludge. The thixotropic

230 property of Laponite at a constant temperature of $25 \pm 1.0^{\circ} \mathrm{C}$, was measured the same way

231 of sludge measurement by applying a pre-shear (corresponding to $400 \mathrm{~s}^{-1}$ ) for 15 minutes

232 then a first shear stress corresponding to a shear rate of $350 \mathrm{~s}^{-1}$ for 15 minutes; a second

233 shear stress corresponding to $100 \mathrm{~s}^{-1}$ for 15 minutes and reapplying the first shear again for

234 another 15 minutes. The resulting shear rate versus time graph was analyzed (Amemiya and

235 Shoemaker, 1992; Baudez, 2008).

\section{3. RESULT AND DISCUSSION}

237 The viscosity flow curve for thickened digested sludge at $3.23 \%$ is presented in Figure 1.

238 As illustrated in Figure 1, this sludge sample can be modelled with Herschel-Bulkley model

239 with shear thinning behaviour which is consistent with other researcher's observation 
240 (Chaari et al., 2003). The parameters of model are $\tau_{y}=1.504 P a, K=0.296 \mathrm{~Pa} . \mathrm{s}^{\mathrm{n}}$, and

$241 \mathrm{n}=0.606$. Figure 2 shows the thixotropic characteristic of thickened digested sludge at $24225^{\circ} \mathrm{C}$.

\subsection{Similarity of sludge rheological behaviour during steady state operation} to the rheology of CMC solution

If only high shear rate range (above $20 \mathrm{~s}^{-1}$ ) of the sludge viscosity curve (Fig.1) is to be considered, one straight line or in another word the power law model is adequate for modelling experimental data. Therefore, sludge at high shear rates and at steady state operation can be modelled similar to CMC at shear rate higher than $10 \mathrm{~s}^{-1}$ with a power-law model although Cross model decries whole shear rate range of CMC solution. Figures 3 show the viscosity curves of different CMC concentrations, respectively.

255 Figure 3 was obtained by combining both SR200 and Rheologica data. But before merging 256 these data, it is required that the raw data from the rheometer to be corrected for the effect 257 of non-Newtonian flow behaviour in the wide gap measurement technique. The true shear 258 rate was determined through the technique described by Coussot (2005). After finding true 259 shear rate and shear stress of fluid in the wide gap of couette geometry, the data was 260 combined with the raw data of SR200 and then the Cross viscosity model (Sybilski, 2011) 
261 was used to describe the flow curve of CMC. In order to determine the Cross model

262 parameters, the error between the predicted viscosity (using the Cross Model) and the

263 measured viscosity according to Eq.7, was minimised. Table 1 shows the Cross model

264 viscosity parameter for various CMC concentrations.

265

$$
S S E=\frac{\left(\mu_{\text {Predicted }}-\mu_{\text {Measured }}\right)^{2}}{\left(\mu_{\text {Measured }}\right)^{2}}
$$

Tab.1: Summary of Cross Model viscosity parameters

\begin{tabular}{llll}
\hline CMC (Wt.\%) & $\mathrm{m}$ & $\mathrm{K}$ & $\mu_{0}$ \\
\hline 0.5 & 0.633 & 0.024 & 0.373 \\
\hline 1 & & & \\
\hline 1.5 & 0.603 & 0.273 & 3.322 \\
\hline
\end{tabular}

268 Figure 3 demonstrates that CMC exhibits shear thinning behaviour similar to sludge at high

269 shear rate and follows the Cross model for power law fluids (Barnes, 1999). The error

270 associated with measured data and Cross model calculations is relatively low suggesting

271 that the Cross model can be used to model the fluid properties of aqueous CMC solutions at

272 low concentrations (Benchabane and Bekkour, 2008). The plateau illustrated in Figure 3

273 suggests that the fluid behaves as a Newtonian fluid at low shear (Barnes and Walters,

274 1985), and also behaves as a non-Newtonian fluid following the power law model at higher 275 shear rates. 


\subsection{Similarity of sludge rheological behaviour during short time process operation to rheology of Carbopol fluid}

The issue of whether yield stress really exists is still debatable until today. The main reason is that no equipment, so far, allows researchers to measure the shear stress of sludge at very low shear rate without being affected by the wall-slip or end effects. Besides that, the concept of yield stress is not well-defined. There is variation in terms of rheological model and experimental method used among researchers to determine yield stress points of a material. It is generally accepted that a rheological model that includes a yield stress term can be used to represent the flow behavior of sludge over a limited shear rate range, but does not necessary indicate that the sludge is a yield stress fluid (Barnes, 1999). Based on a review paper by Seyssiecq et al. (2003), with apparatus being more advanced, it is commonly admitted among researchers that yield stress does exist in aggregated concentrated sludge.

Yield stress is defined as minimum stress that needs to be applied for a material to flow steadily. It is generally agreed among researchers that yield stress tends to increase as the solid concentration of sludge becomes higher, even for pre-treated or conditioned sludge (Mikkelsen, 2001; Forster, 2002; Seyssiecq et al., 2003; Spinosa and Lotito, 2003; Wilen et al., 2003, Khongnakorn et al., 2010;)

The viscosity curve for Carbopol in Figure 4 is plotted by using data obtained from SR200.

The Herschel-Bulkley model was fitted to the data and its parameters are presented in Table 2. It is evident that Carbopol at the studied concentrations follows the Herschel-Bulkley Fluid model with shear thinning behaviour as illustrated a value below one for ' $\mathrm{n}$ '. A 
299 critical yield stress must be applied in order for Carbopol to flow, which is evident for all

300 Carbopol concentrations; this also increases with increasing concentration. Coussot et al.

301 (2009) also highlighted Carbopol gel as a type of material which can be an excellent model

302 for yield stress fluid. Therefore Carbopol will be a suitable material for studying the yield

303 stress effect on sludge for different short time process such as pumping.

304 Tab.2: Rheological properties of Carbopol using the Herschel-Bulkley fluid Model

\begin{tabular}{llll}
\hline Carbopol (Wt. \%) & $\mathrm{n}$ & $\mathrm{K}$ & $\tau_{y}$ \\
\hline 0.1 & & & \\
& 0.513 & 3.2 & 24.50 \\
\hline 0.5 & & & \\
\hline 1.0 & 0.502 & 27.50 & 118.33 \\
\hline 1.5 & 0.484 & 37.20 & 143.20 \\
\hline & & & \\
\hline
\end{tabular}

305

306 Fig.4: Viscosity curves for $0.1 \%(\diamond), 0.5 \%(\Delta), 1.0 \%(\square)$ and $1.5 \%(0)$ Carbopol samples

307 This study's observation is consistent with the results of the other researchers (Curran et al., 308 2002; Putz and Burghelea, 2009; Gomez et al., 2010,).

310 These results are compared with other researchers who also have investigated the

311 rheological properties of Carbopol in their works in various applications (Table 3). It is

312 agreed among researchers that the Herschel-Bulkley model fluid is a suitable model to

313 describe the behaviour of Carbopol solution at various concentrations (Roberts and Barnes, 
314 2001; Kim et al., 2003; Coussot et al. 2009; Gomez et al., 2010), but none of them use

315 Carbopol as model fluid for sludge.

316

317 Tab.3: Rheological characterization of Carbopol for various applications

\begin{tabular}{llll}
\hline Author & Year & Application & Suspension \\
& & & $(\%)$ \\
& & & concentration \\
& & & $0.045-1.00$ \\
\hline Robert and Barnes & 2001 & Examine slip effect on Carbopol dispersion & $0.1-4.0$ \\
\hline Kim et al. & 2003 & Evaluate viscoelastic property of Carbopol & 0.1 \\
\hline Gomez et al. & 2010 & Model fluid for pulp mixing & $0.1-1.5$
\end{tabular}

319 In general, behaviour of Carbopol may seem similar to sludge as it is shear thinning and

320 exhibit yield stress. As suspension concentration increases, both viscosity as well as yield

321 stress of sludge and Carbopol increases. However, it is well known that Carbopol is a more

322 stable system, i.e. non-thixotropy (Moller et al., 2009) when compare to sludge, therefore

323 making it suitable to be used as a model fluid for sludge when thixotropic property is not a

324 major concern.

\section{3.2Time characteristic of sludge}

326 Figure 2 demonstrates that the property of sludge depends on shear history and processes

327 that the sludge undergoes. Indeed, thixotropy demonstrates time-dependency of sludge

328 structural changes at a given shear rate which is indication of a competition between

329 flocculation and de-flocculation (Baudez, 2008). In practice, there is a possibility of 
330 clogging the sludge transportation pipeline if the wall shear stress is to be below critical

331 shear stress (yield stress). Because at shear stress below yield stress, the earlier

332 deflocculated sludge will re-flocculates, and solid characteristic becomes predominant

333 during shear (Baudez, 2008) and gradually solid deposition builds up from wall to the

334 centre of the pipe. In Figure 2, there is $17 \%$ difference between shear rate data obtained for

335 the same imposed shear stress (at the first and final stage) corresponding to $100 \mathrm{~s}^{-1}$ shear

336 rate.. This indicates that the sludge flocculated again when the shear rate dropped from 100

$337 \mathrm{~s}^{-1}$ to $5 \mathrm{~s}^{-1}$ and for this reason, the response for final and the same shear stress is not the

338 same as of the first one. Because before the first shear at $100 \mathrm{~s}^{-1}$, sludge undergoes a pre-

339 shearing stress at $200 \mathrm{~s}^{-1}$, but before the final shear at $100 \mathrm{~s}^{-1}$, sludge undergoes shear at $5 \mathrm{~s}^{-}$

340 ' , which demonstrates the thixotropic behaviour of the sludge. This characteristic of sludge

341 is important when sludge undergoes different shearing stress. For example, there is a

342 difference between the shearing stress in a heat exchanger and inside of anaerobic digester.

343 Therefore, it is important to consider thixotropic property (flocculation and de-flocculation)

344 of sludge for all engineering design such as pipeline design for pumping or heating purpose

345 in order to prevent clogging; mixing system design in order to prevent deposition of sludge

346 at the bottom of tank. Using external heat exchangers is common in wastewater treatment

347 plant in order to keep anaerobic digester temperature constant at $37^{\circ} \mathrm{C}$ or $55^{\circ} \mathrm{C}$ depending

348 on mesophilic or thermophilic condition. Thus, choosing a clear model fluid which can

349 capture the time dependent characteristics of the sludge in the anaerobic digester is

350 important. 
351 The viscosity curve of Laponite clay can also be modelled with the Herschel-Bulkley

352 model which is presented in Figure 5. Like Carbopol, Laponite presents shear thinning

353 behaviour $(\mathrm{n}<1)$ with a critical shear stress and rate which below that there is no flow. In

354 Figure 5, it is evident that Laponite viscosity increases as the suspension concentration is

355 increased. Table 5 demonstrates that the parameters of this model ( ' $\mathrm{K}$ ', ' $\mathrm{n}$ ' and $\tau_{y}$ ).

359 Fig. 5: Viscosity curve for different concentration of Laponite: $1.0 \%(\bullet), 2.0 \%(\mathrm{X}), 2.5 \%$

Tab.5. Rheological properties of Laponite using the Herschel-Bulkley fluid Model

\begin{tabular}{llll}
\hline Laponite (Wt. \%) & $\mathrm{n}$ & $\mathrm{K}$ & $\tau_{y}$ \\
\hline 1.0 & 0.90 & 0.01 & 0.001 \\
\hline 2.0 & & & \\
\hline 2.5 & 0.38 & 0.78 & 0.587 \\
\hline 3.0 & 0.36 & 2.06 & 3.205 \\
\hline 3.5 & 0.34 & 2.41 & 17.614 \\
\hline 4.5 & 0.32 & 3.96 & 29.818 \\
\hline
\end{tabular}

364 Figure 6 clearly shows that the Laponite possesses thixotropic properties. In this paper, it is observed that the thixotropic effect cannot be correlated to the rest time or even suspension 
concentration. There is no clear trend or pattern in suggesting whether thixotropy becomes more apparent or not as the rest-time or suspension concentration is increased. Also it is noticed that the thixotropic test results are not reproducible and may vary by several orders

369 of magnitude even if the experimental conditions were to remain the same. The thixotropic

370 effect of Laponite might not be apparent over a short rest time difference. Many researchers

371 have investigated the thixotropic properties of Laponite on daily basis or over the course of

372 a longer period (Joshi et al., 2008; Labanda and Llorens, 2008) based on the change in

373 rheological properties (Knabel et al., 2000; Labanda and Llorens, 2008).

Fig.6: Thixotropic behaviour of Laponite with 30 minutes rest time between each shear:

378 It seems that Laponite has proved to be a better model fluid for sludge compared to

379 Carbopol as it can capture both the yield stress and thixotropic properties of digested

380 sludge, as well as presenting with similar rheogram curvature, as is demonstrated in Figure

381 7. Unlike Carbopol, Laponite may be a temperature sensitive fluid, as indicated by the

382 work of Shukla and Joshi (2008), which is important as sludge rheology is affected by

383 thermal history (Baudez et al., 2011b). Nevertheless, further investigations need to be done 384 to examine the effect of physical chemistry such as surface charge or temperature on the 385 rheology of Laponite and compare it to sludge.

387 Fig.7: Comparative flow curves of all model fluids a) Carbopol, b) Laponite and c) CMC) with $3.23 \%$ digested sludge 


\section{CONCLUSION}

391 A thickened digested sludge has been rheologically characterized and the results showed

392 shear-thinning with time dependent (thixotropic characteristics) behaviour for samples

393 taken from one of Melbourne's wastewater treatment plants. Candidate transparent fluid

394 model materials to mimic the sludge behaviour were also rheologically characterised. In

395 comparison between real sludge and model fluid, it was concluded that the real sludge in

396 steady sate and at high shear rate operation such as pipe flow, mixing, aeration can be

397 modelled by a basic power-law approach, similar to CMC. Also, Carbopol can be a good

398 proxy for real sludge for short-time processes such as pumping and its liquid-like property

399 can be modelled with the Herschel-Bulkley model. The time characteristic of sludge can be

400 modelled using Laponite clay, but further study is required at different temperatures in

401 order ensure that Laponite can emulate behavioural changes due to temperature variation.

\section{ACKNOWLEDGMENT}

403 The authors are very grateful for financial support of Melbourne Water and South East

404 Water (Ltd.) as well as the Research and Innovation Office of RMIT University.

405 REFERENCES

406 Amemiya, J.I., Shoemaker,C.F., 1992. Measurement of thixotropy of model food colloidal 407 suspensions with step change shear rate. Journal of Food Enginneering 16(1-2), 17-24. 
409 Barnes, H.A., 1999. The yield stress - a review or ' $\pi \alpha v \tau \alpha \rho \varepsilon$ ' - everything flows. Journal

410 of Non-Newtonian Fluid Mechanics 81(1-2), 133-178.

411

412 Barnes, H.A., Walters, K., 1985. The yield stress myth? Rheologica Acta 24(4), 323-326.

413

414 Baudez, J.C., 2001. Rhéologie et physico-chimie des boues résiduaires pâteuses pour

415 l'étude du stockage et de l'épandage. PhD Thesis, Ecole Nationale du Génie Rural, des

416 Eaux et Forêts, Paris.

417

418 Baudez, J.C., 2006. About peak and loop in sludge rheograms. Journal of Environmental

419 Management 78(3), 232-239.

420

421 Baudez, J.C., 2008. Physical aging and thixotropy in sludge rheology. Applied Rheology

$42218(1), 13459-13466$.

423

424 Baudez, J.C, Coussot, P., 2001. Rheology of aging, concentrated, polymeric suspensions:

425 Application to pasty sewage sludges. Journal of Rheolology 45 (5), 1123-1139.

426

427 Baudez, J.C., Markis, F., Eshtiaghi, N., Slatter, P., 2011a. The rheological behaviour of 428 digested sludge. Water Research, 45, 17, 5675-5680

429 
430 Baudez, J.C., Gupta, R., Eshthiaghi, N., Parthasarathy, R., Slatter, P.T., 2011b. Digested

431 sludge rheology: similarities with soft glassy materials. Chemeca 2011, 18-21 Sept., 432 Sydney, Australia

433

434 Baudez, J.C., Ginisty, P., Peuchot, C., Spinosa, L., 2007. The preparation of synthetic 435 sludge for lab testing. Water Science \& Technology 56 (9), 67-74.

436

437 Benchabane, A., Bekkour,K., 2008. Rheological properties of carboxymethyl cellulose 438 (CMC) solutions. Colloid \& Polymer Science 286 (10), 1173-1180.

Bhattacharya. S.N., 1981. Flow characteristics of primary and digested sewage sludge.

$441 \quad$ Rheologica Acta 20 (3), 288- 298.

442

443 Bongiovanni, M., 1998. Residual sludge treatment by combination in series of mechanical 444 dewatering and thermal drying. PhD dissertions, University of Pau

446 Bonn, D., Coussot, P., Huynh, H.T., Bertrand,F., Debrégeas, G., 2002. Rheology of soft 447 glassy materials. Europhysics Letters 59(5), 786-792.

449 Bonn, D., Kellay H., Tanaka, H., Wegdam, G., Meunier, J., 1999. Laponite: What is the 450 difference between a gel and a glass? Langmuir 15(22), 7534-7536. 
452 Campbell, H.W., Crescuolo, P.J, 1982. The use of rheology for sludge characterisation.

453 Water Science \& Technology 14(6-7), 475-489.

455 Chaari, F., Racineux, G., Poitou,A., Chaouche, M., 2003. Rheological behaviour of sewage 456 sludge and strain-induced dewatering. Rheologica Acta 42(3), 273-279.

458 Chhabra, R.P., Richardson, J.F., 2008. Non-Newtonian flow and applied rheology 459 engineering applications ( $2^{\text {nd }}$ Edition). Elsevier.

460

461 Colin, F., 1970. Application de techniques rhéologiques à l'étude des boues résiduaires.

462 Centre Belge d'Etude et de Documentation des Eaux. 317, 178-187

463

464 Coussot, P., 2005. Rheometry of pastes, suspensions, and granular materials: Applications 465 in industry and environment. John Wiley \& Sons, Inc., Hoboken, NJ, USA.

467 Coussot, P., Tocquer, L., Lanos, C., Ovarlez, G., 2009. Macroscopic vs. local rheology of 468 yield stress fluids. Journal of Non-Newtonian Fluid Mechanics 158(1-3), 85-90

470 Curran, S.J., Hayes, R.E., Afacan, A., Williams, M.C., Tanguy, P.A., 2002. Properties of 471 Carbopol solutions as models for yield-stress fluids. Journal of Food Science 67 (1), 176472180. 
474 Dursun, D., Ayol, A., Dentel, S.K., 2004. Physical characteristics of a waste activated

475 sludge: conditioning responses and correlations with a synthetic surrogate. Water Science 476 \& Technology 50 (9), 129-136.

477

478 Forster, C. F., 2002. The rheological and physico-chemical characteristics of sewage 479 sludges. Enzyme and Microbial Technology 30(3), 340-345.

481 Gomez, C., Derakhshandeh, B., Hatzikiriakos,S.G., Benninton, P.J., 2010. Carbopol as a 482 model fluid for studying mixing of pulp fibre suspensions. Chemical Engineering Science, $483 \quad 65(3), 1288-1295$

485 Guibaud, G., Dollet, P., Tixier, N., Dagot, C., Baudu, M., 2003. Characterization of the 486 evolution of activated sludges using rheological measurements. Process Biochemistry $487 \quad 39(11), 1803-1810$.

488

489 Héritier, P., Roux, J.C., Dieudé-Fauvel, E., 2010. Impact of sludge mechanical behaviour 490 on spatial distribution parameters obtained with centrifugal spreader. AgEng 2010, 491 International Conference on Agricultural Engineering, France.

492

493 Jorand, F., Zartarian, F., Thomas, F., Block, J. C., Bottero, J. Y., Villemin, G., Urbain, V. 494 Manem, J., 1995. Chemical and structural (2D) linkage between bacteria within activated 495 sludge flocs. Water Research 29(7), 1639-1647.

496 
497 Joshi, Y. M., Reddy, G. R. K., Kulkarni, A. L., Kumar, N., Chhabra, R. P., 2008.

498 Rheological behaviour of aqueous suspensions of laponite: new insights into the ageing 499 phenomena. Proceedings of the Royal Society A: Mathematical, Physical and Engineering $500 \quad$ Science 464(2090), 469-489.

502 Khongnakorn, W., Mori, M., Vachoud,L., Delalonde,M.L., Wisniewski, C., 2010. 503 Rheological properties of sMBR sludge under unsteady state conditions. Desalination 250 504 (2), 824-828.

505

506 Kim, J.Y., Song, J.Y., Lee E.J., Park S.K., 2003. Rheological properties and 507 microstructures of Carbopol gel network system. Colloid \& Polymer Science 281(7), 614508623.

510 King, H. E. Jr., Milner, S. T., Lin, M. Y., Singh, J. P., Mason, T. G., 2007. Structure and 511 rheology of organoclay suspensions. Physical Review E Stat Nonlin Soft Matter Phy 75 (2), 512021403.

514 Knabel, A., Bellour, M., Munch, J.P., Viasnoff, V., Lequeux, F., Hardem,J.L., 2000. Aging 515 behavior of Laponite clay particle suspensions. Europhysics Letter 52 (1), 73 - 79.

517 Labanda, J., Llorens, J., 2008. Effect of aging time on the rheology of Laponite dispersions. 518 Colloids and Surfaces A: Physicochemical and Engineering Aspects 329(1-2), 1-6. 
520 Laera, G., Giordano, C., Pollice, A., Saturno, A., Mininni,G., 2007. Membrane bioreactor

521 sludge rheology at different solid retention times. Water Research 41 (18), 4197-4203.

523 Legrand, V., Hourdet, D., Audebert,R., Snidaro,D., 1998. Deswelling and flocculation of 524 gel networks: application to sludge dewatering. Water Research 32 (12), 3662-3672.

526 Masalova, I., Malkin, A.Y., Kharatiyan, E., Haldenwang,R., 2006. Scaling in pipeline flow 527 of Kaolin suspensions. Journal of Non-Newtonian Fluid Mechanics 136 (1), 76-78.

528

529 Mikkelsen, L.H., 2001. The shear sensitivity of activated sludge: Relations to filterability, 530 rheology and surface chemistry. Colloids and Surfaces A: Physicochemical and 531 Engineering Aspects 182 (1-3), 1-14

533 Moeller, G., Torres, L.G., 1997. Rheological characterization of primary and secondary 534 sludges treated by both aerobic and anaerobic digestion. Bioresource Technology 61(3) $535 \quad 207-211$.

537 Moller, P.C.F., FALL, A., Bonn, D., 2009. No steady state flows below the yield stress. A 538 true yield stress at last? ArXiv:0904.1467v1.

540 Mori, M., Seyssiecq, I., Roche, N., 2006. Rheological measurements of sewage sludge for 541 various solids concentrations and geometry. Process Biochemistry 41 (7), 1656-1662. 
543 Müller, J.A., Dentel. S. K., 2002. Optimistion of floc-stability by mechanical pre- and post-

544 Stressing. Chemical Water and Wastewater Treatment VII IWA Publishing, London.

546 Nguyen, T. P., Hankins, N. P., Hilal, N., 2007a. A comparative study of the flocculation 547 behaviour and final properties of synthetic and activated sludge in wastewater treatment. 548 Desalination 204 (1-3), 277-295.

550 Nguyen, T. P., Hankins, N. P., Hilal, N. 2007b. Effect of chemical composition on the 551 flocculation dynamics of latex-based synthetic activated sludge. Journal of Hazardous 552 Materials $139(2), 265-274$.

554 Nguyen, T. P., Hilal, N., Hankins, N. P., Novak, J. T., 2008. Determination of the effect of 555 cations and cationic polyelectrolytes on the characteristics and final properties of synthetic 556 and activated sludge. Desalination $222(1-3), 307-317$

558 Norbert, W., 1996. Unusual Thixotropic Properties of Aqueous Dispersions of Laponite 559 RD. Journal of Colloid and Interface Science, 182, 501-510

561 Örmeci, B., Vesilind, P. A., 2000. Development of an improved synthetic sludge: a possible 562 surrogate for studying activated sludge dewatering characteristics. Water Research 34 (4), $563 \quad 1069-1078$ 
565 Putz, A. , Burghelea, T., 2009. The solid-fluid transition in a yield stress shear thinning

566 physical gel. Rheologica Acta 48 (6), 673-689.

568 Roberts, G. P., Barnes, H. A., 2001. New measurements of the flow-curves for Carbopol 569 dispersions without slip artefacts. Rheologica Acta 40 (5), 499-503.

571 Sanin, D.F., Vesilind, P. A., 1996. Synthetic sludge: A physical/ chemical model in 572 understanding bioflocculation. Water Environment Research 68 (5), 927-933.

573

574 Seyssiecq, I., Ferrasse, J.H., Roche, N., 2003. State-of-the-art: rheological characterisation 575 of wastewater treatment sludge. Biochemical Engineering Journal 16 (1), 41-56.

576

577 Shukla, A., Joshi, Y.M., 2008. Ageing under Shear: Effect of Stress and Temperature Field. 578 AIP Conference Proceedings 1027(1), 1018-1020.

580 Slatter, P.T., 1997. The rheological characterisation of sludges. Water Science \& 581 Technology $36(11), 9-18$.

582

583 Slatter, P.T., 1999. The laminar/turbulent transition prediction for non-Newtonian slurries.

584 Proceedings of the International Conference 'Problems in Fluid Mechanics and 585 Hydrology', Academy of Sciences of the Czech Republic, Prague. June 23-26, 247-256. 
587 Slatter, P.T., 2008. Pipe flow of highly concentrated sludge. Journal of Environmental

588 Science and Health Part A 43(13), 1516-1520.

590 Slatter, P.T., 2011. The engineering hydrodynamics of viscoplastic suspensions. Journal of 591 Particulate Science and Technology 29(2), 139-150.

593 Sozanski, M. M., Kempa, E. S., Grocholski, K., Bien, J., 1997. The rheological experiment 594 in sludge properties research. Water Science \& Technology 36(11), 69-78.

596 Spinosa, L., 2001. Evolution of sewage sludge regulations in Europe. Water Science \& 597 Technology 44(10), 1-8.

598

599 Spinosa, L., Lotito, V., 2003. A simple method for evaluating sludge yield stress. Advances 600 in Environmental Research 7(3), 655-659.

601

602 Spinosa, L., Wichmann, K., 2004. Sludge characterisation: the role of physical consistency. 603 Water Science \& Technology 49(10), 59-65.

604

605 Sybilski, D., 2011. Zero-shear viscosity of bituminous binder and its relation to bituminous 606 mixture's rutting resistance. Transport Research Record 1535(1), 15-21.

607 
608 Tabuteau, H., Coussot, P., Baudez, J.C., 2006. A new approach to the thixotropic behaviour

609 of sewage sludge. Journal of Residuals Science and Technology, Volume 3, Issue 4,

610 October 2006, Pages 233-240.

611

612 Terashima, M., Goel, R., Komatsu, K., Yasui, H., Takahashi, H., Li, Y.Y., Noke, T., 2009.

613 CFD simulation of mixing in anaerobic digesters. Bioresource Technology 100 (7), 2228-

6142233.

615

616 Tixier, N., Guibaud, G., Baudu, M., 2003. Towards a rheological parameter for activated

617 sludge bulking characterisation. Enzyme and Microbial Technology 33(2-3), 292-298.

618

619 Valioulis, I., 1980. Relationship between settling, dewatering and rheological properties of 620 activated sludge. Master of Science Thesis, Cornell University, New-York, USA.

621

622 Wilen, B.M., Jin, B., Lant, P., 2003. The influence of key chemical constituents in activated

623 sludge on surface and flocculating properties. Water Research 37 (9), 2127-2139.

624

625

626 


\section{$\underline{\text { Research highlights: }}$}

Real sludge can be modelled:

- As non-Newtonian shear thinning thixotropic material

- In steady sate, and at high shear rate operation with a power-law similar to CMC

- In short-time processes such as pumping with carbopol and the Herschel-Bulkley model

- With laponite for thixotropic property characterization 


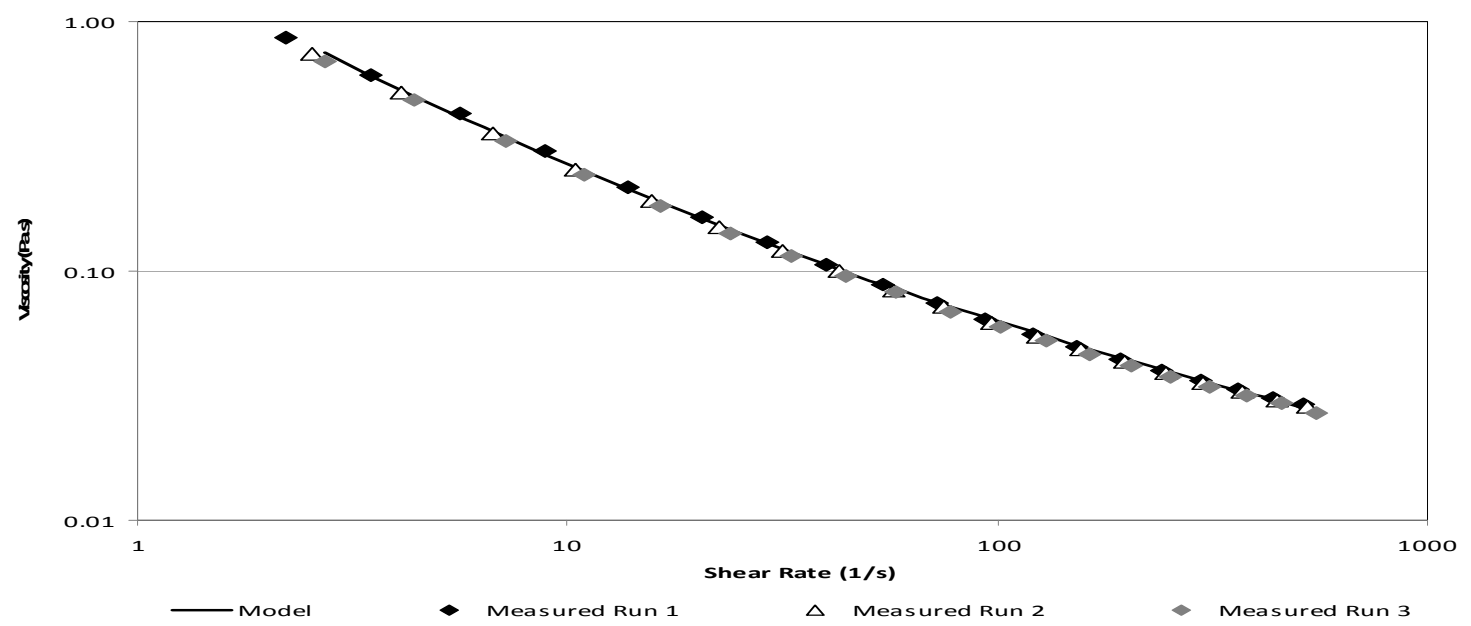

Fig.1: Viscosity curve of thickened digested sludge with $3.23 \% \mathrm{TSS}$ at $25^{\circ} \mathrm{C}$

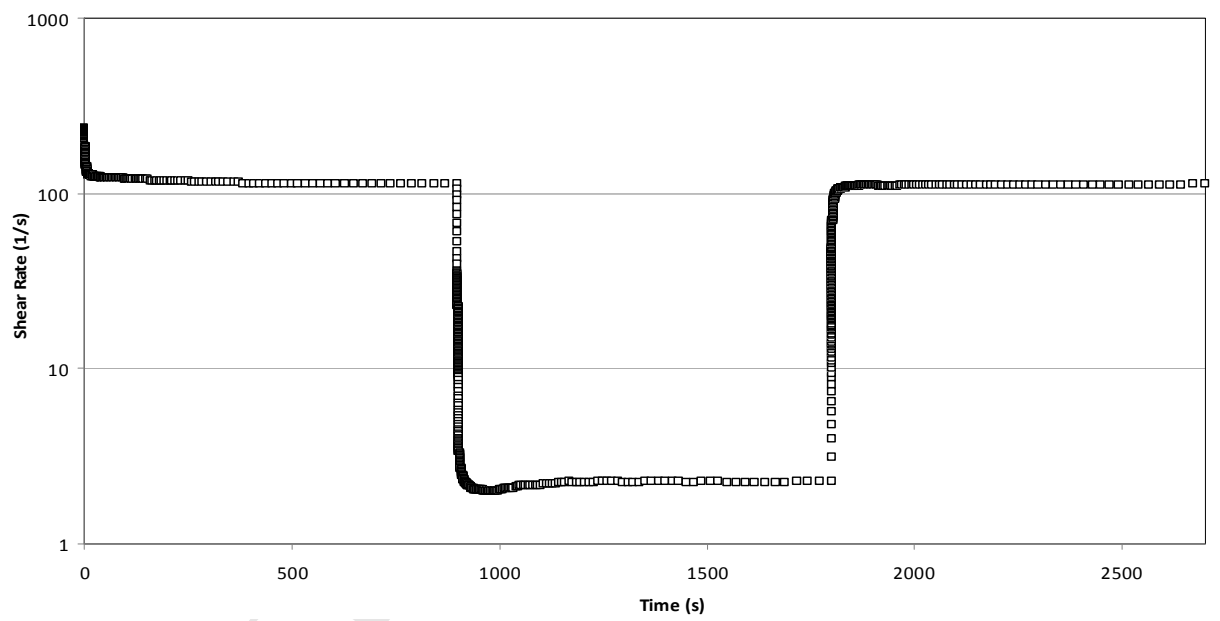

Fig.2: Thixotropic behaviour of thickened digested sludge with $3.23 \% \mathrm{TSS}$ at $25^{\circ} \mathrm{C}$ 


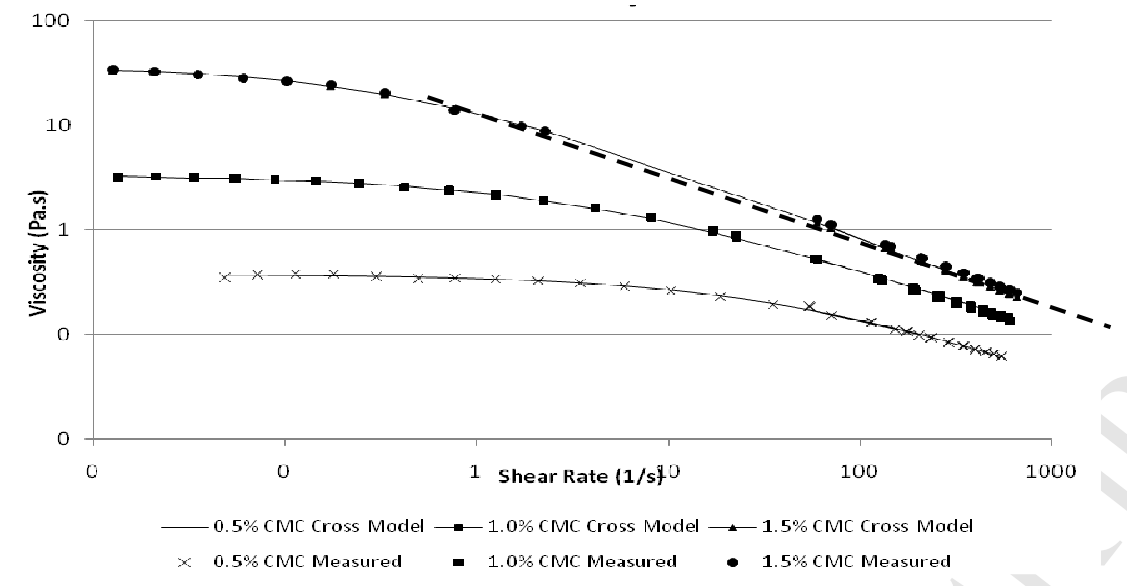

Fig.3: Viscosity Curve of different CMC concentrations

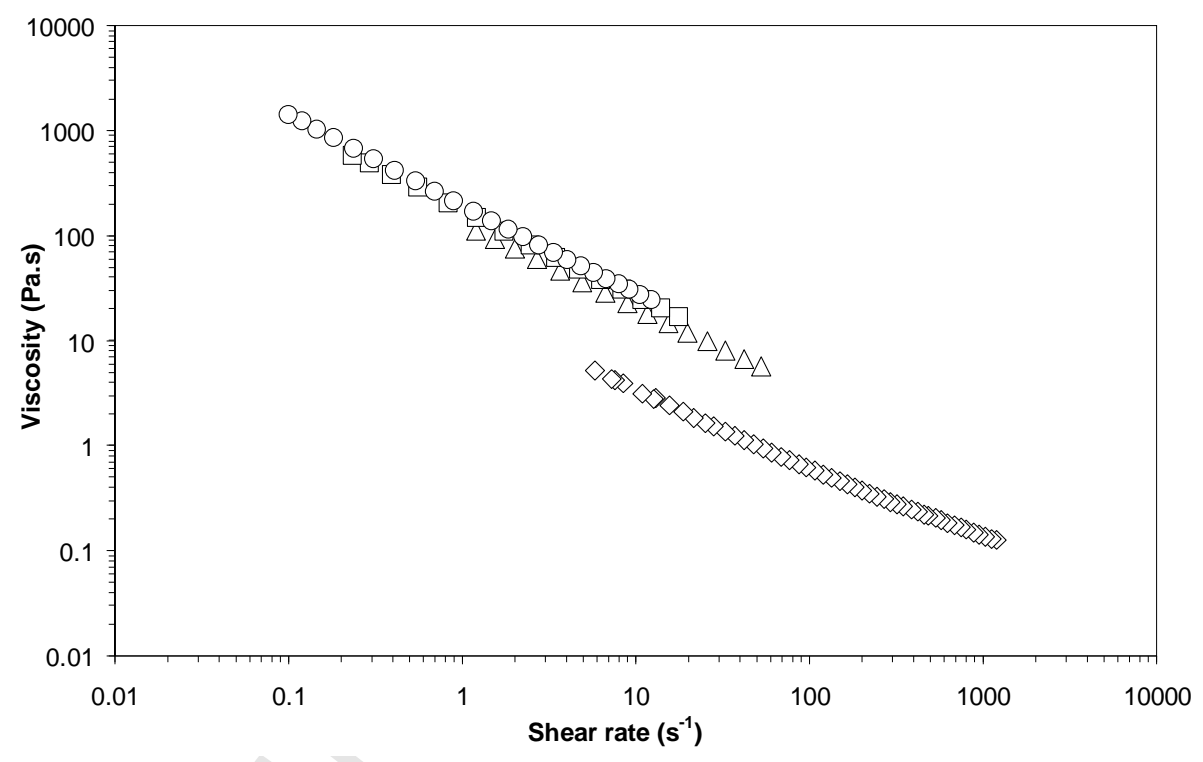

Fig.4: Viscosity curves for $0.1 \%(\diamond), 0.5 \%(\Delta), 1.0 \%(\square)$ and $1.5 \%(\circ)$ Carbopol samples 


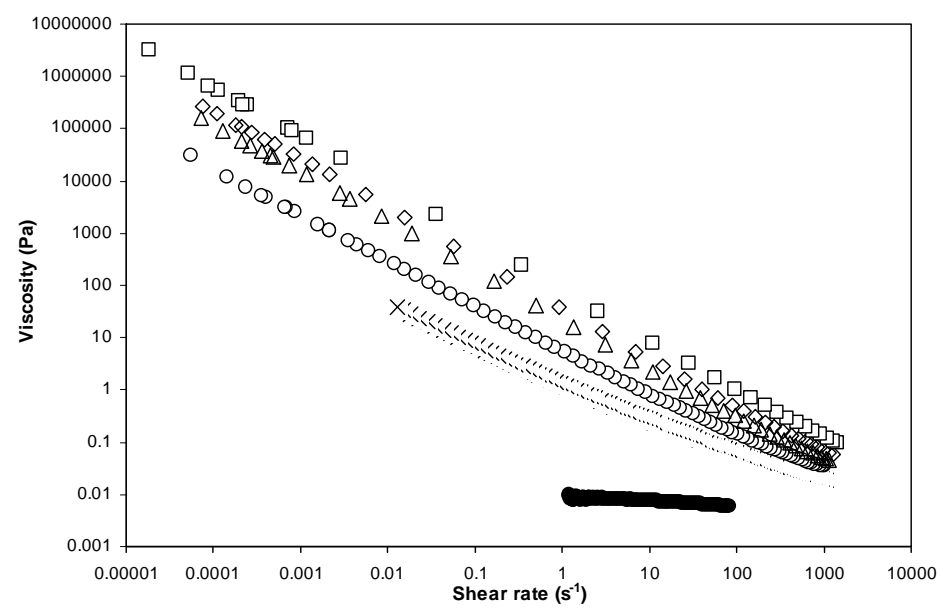

Fig. 5: Viscosity curve for different concentration of Laponite: $1.0 \%(\bullet), 2.0 \%(\mathrm{X}), 2.5 \%(0), 3.0 \%(\Delta), 3.5 \%$ $(\diamond)$ and $4.5 \%(\square)$

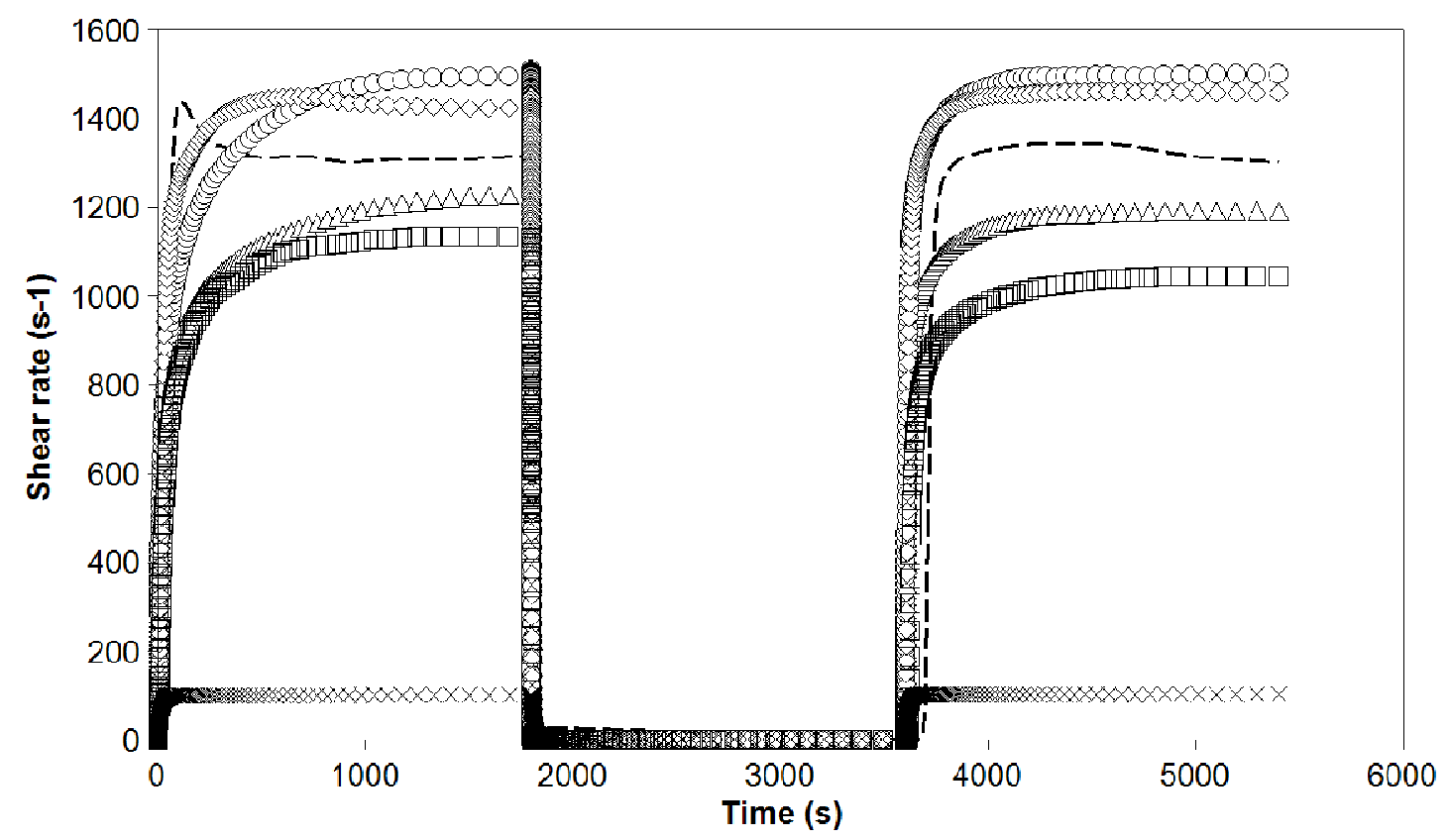

Fig.6: Thixotropic behaviour of Laponite with 30 minutes rest time between each shear: 1.0\% (X), $2.0 \%(\Delta)$, $2.5 \%(\circ), 3.0(\diamond)$ and $3.5 \%(\square)$ and $4.5 \%(--)$ 


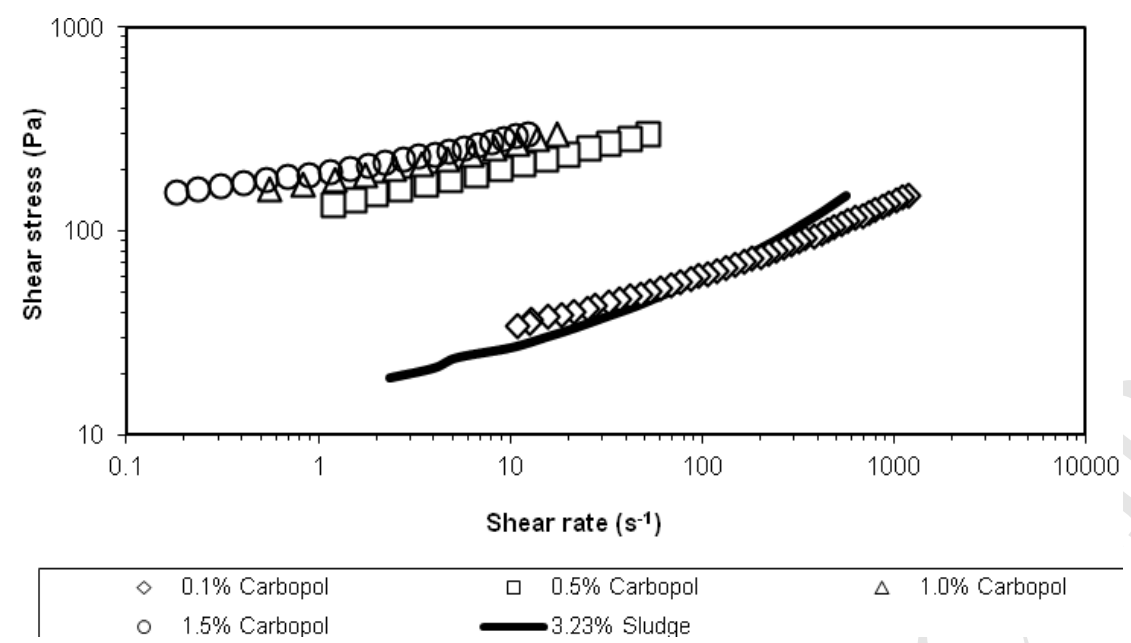

(a)

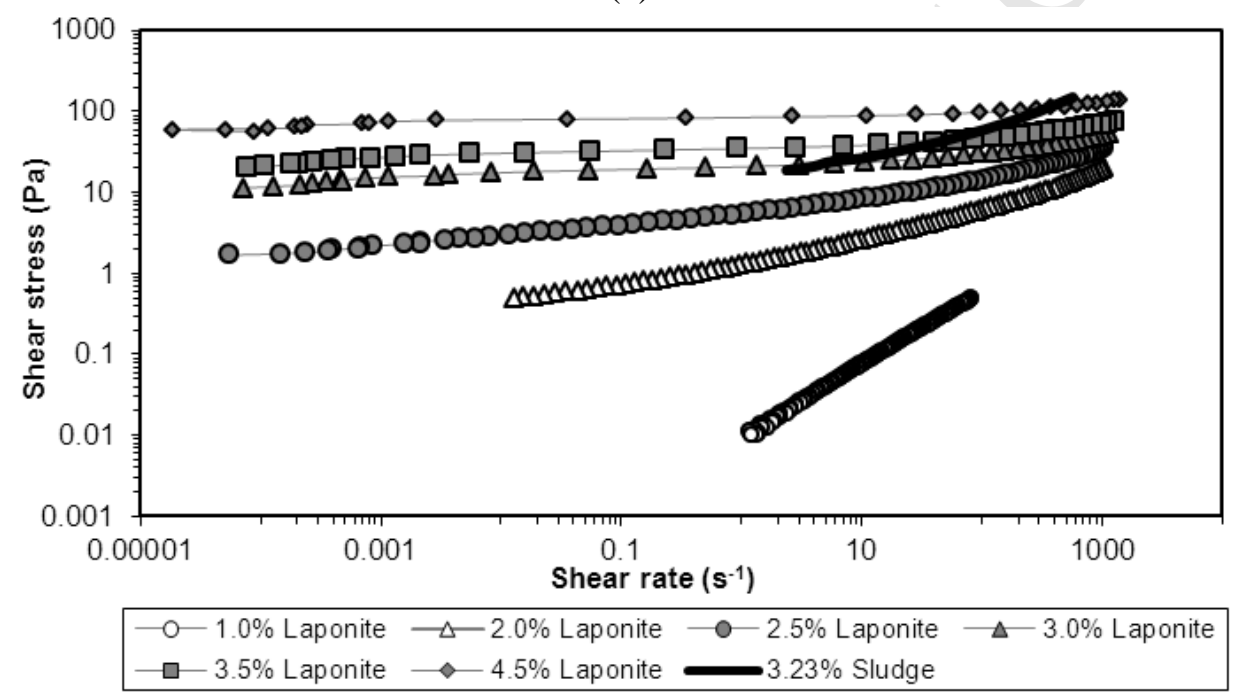

(b)

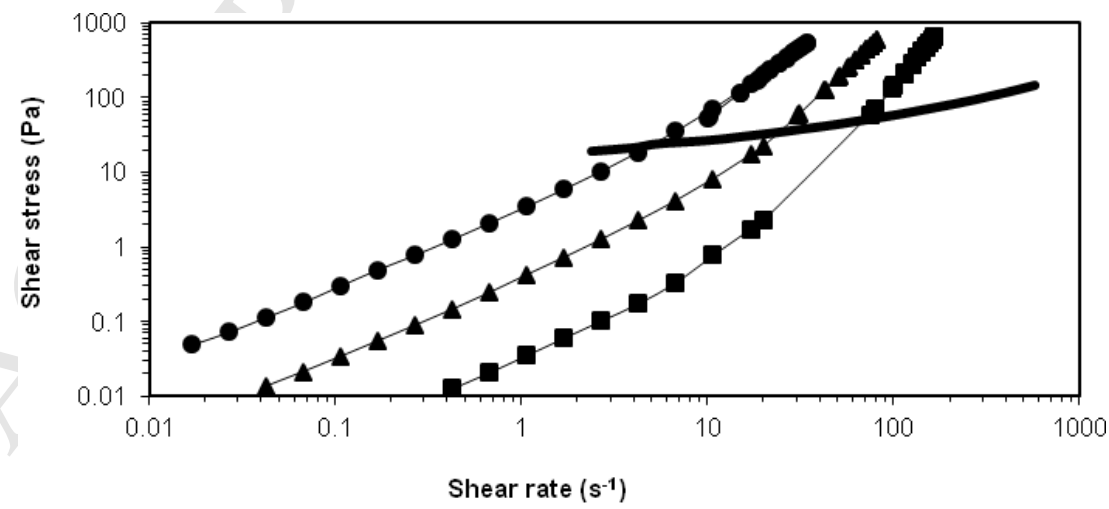

$\longrightarrow 0.5 \% \mathrm{CMC} \rightarrow 1.0 \% \mathrm{CMC} \rightarrow-1.5 \% \mathrm{CMC} \longrightarrow 3.23 \%$ Sludge

(c) 
Fig.7: Comparative flow curves of all model fluids a) Carbopol, b) Laponite and c) CMC) with 3.23\% digested sludge 